\title{
Fantasies, Micro-Identity, and Web 2.0
}

\author{
CHRISTOPHER GARLAND - University of Florida, USA
}

\begin{abstract}
This essay discusses how social networking site-styled "adult" websites facilitate online socialization through shared "fantasies." Moreover, and perhaps more crucially, this essay also explores how users on these websites construct identity online. I argue that the development of Web 2.0 has changed significantly changed the form and use of Internet pornography, and those who engage in "Porn 2.0" are part of a significant (if impossible to accurately measure) Web 2.0 community. Furthermore, I seek to interrogate the limits involved with the performance of micro-identity on the Porn 2.0 stage - focusing on sites that largely provide pornographic video and live web chats-while also taking into account the ethical considerations that accompany the Porn 2.0 landscape.
\end{abstract}

\section{KEYWORDS}

Porn 2.0, Micro-identity, Social networks, Intimacy, YouTube, Web 2.0, Amateur

\section{Introduction}

'For the realm of phantasy depends for its effect on the fact that its content is not submitted to reality-testing' - Sigmund Freud, "The Uncanny"

In a 2007 study titled "Analysis of Topological Characteristics of Huge Online Social Networking Services," the authors claim that social networking sites "attract nearly half of all web users" (1). Over the last few years, with the growth of Facebook from a mostly American, largely college student membership to a rapidly increasing amount of new users from around the world - in addition to the more recent rise of Twitter and the increasingly interactive elements of YouTube-social networking sites (SNSs) have become an increasingly pervasive and allencompassing part of the Internet. While much of the academic and mainstream discourse on SNSs concerns the established outlets of Facebook, MySpace, YouTube, and Twitter, little attention has been given to pornographic websites as locations of innovative and multidimensional social networking. In particular, when discussion of pornography and SNSs arises, it often relates to how the aforementioned SNSs screen for and ban pornographic videos and stills, alongside other so-called inappropriate material. But the growth of free, video-sharing, Web 2.0 pornographic websites - a trend that has been referred to as "Porn 2.0"-is a significant online movement. According to Britain's The Observer, "sites such as YouPorn and Pornotube draw more internet traffic than CNN" (Helmore). 
Unlike pornographic websites a decade ago, Porn 2.0 relies on user participation: "Like YouTube, the phenomenally popular Google-owned website, X-rated sites depend on users streaming videos to the site-and YouPorn is adding 15 million new users a month" (ibid). Also, a number of these pornographic websites have incorporated other elements of SNSs-by way of live camera chats, forums, the ability to upload video, comments sections, sign-in membership, and links to other SNSs - which increase the sense of community online. Patricia Lange asserts the following: "YouTube users employ the technical and social affordances of the site to calibrate access to their videos by members of their social circle," and that "video sharing can support social networks by facilitating socialization among dispersed friends." Both of these claims could, to a certain degree, just as readily be made about Porn 2.0 websites. Taking a lead from the idea of Porn 2.0 allowing greater "audience participation" than any other form of pornography, this essay discusses how SNS-styled pornographic websites facilitate online socialization; however, and perhaps more crucially, this essay also explores how users on these websites construct micro-identities online. Intimate (in terms of the so-called "explicit" and "private" visual material) but often anonymous, temporary and yet permanent (as when an uploaded video goes into cyber-circulation), the micro-identities of those who use Porn 2.0 contribute to a significant, if impossible to accurately measure, segment of total Internet users. Furthermore, I seek to interrogate the limits involved with the performance of micro-identity on the Porn 2.0 stage - focusing on sites that largely provide pornographic video and live web chats-while also taking into account the ethical considerations that accompany the use of Porn 2.0 websites.

\section{From "YouTube to RedTube"}

The rise of Porn 2.0 is directly related to the Internet's ever-increasing breadth and sophistication. It is well documented that since the advent of the World Wide Web, pornographic material has made up a sizeable portion of the content available either for free or via user-pays means. Even as the U.S. Department of Justice contends that only $1.1 \%$ of websites indexed by Google are sexually explicit, Phillip Stark, a professor of statistics at the University of California, Berkeley, claims that the most popular searches list at least one sexually explicit site $40 \%$ of the time: "Sexually explicit websites," Stark adds, "seem to be disproportionately popular" (Stark qtd. in Arthur). There are, of course, numerous websites that are not readily accessible through a basic Google search. But it is only in the last four or five years that the combination of computer software and hardware that enables Porn 2.0's existence has become readily available at relatively low costs. This includes the widespread use of high-quality cameras, fast-streaming video, high-speed broadband connections, user-friendly interfaces, an array of websites with the capacity for massive video repositories, and easy and effective uploading and downloading options.

Accompanying these technological developments is the burgeoning culture of online interactivity and connectivity by and between users, which is one of the fundamental characteristics of the entire Web 2.0 phenomenon. ${ }^{1}$ And the mainstream media has responded to the expansion of the World Keeping with its long-standing tradition of selecting a "Person of the Year," Time recognized this aspect of contemporary online behavior by choosing "You" as its most significant human of 2006 (a year after the term Web 2.0 was coined). In the description of why 
You are important, Lev Grossman evokes the global implications of millions of subjects engaged in Web 2.0:

[It] is a massive social experiment, and like any experiment worth trying, it could fail. There's no road map for how an organism that's not a bacterium lives and works on together on this planet in numbers in excess of 6 billion . . This is an opportunity to build a new kind of international understanding, not politician to politician, great man to great man, but citizen to citizen, person to person.

I quote at length from Grossman's piece not to endorse his utopian view of the potentialities of online connectivity, but rather because no matter what this moment in the evolution of human interaction might be-revolutionary, beguiling, invasive, perhaps all of the above-Porn 2.0 is part of it. The You who Grossman claims are engaged in building "a new kind of international understanding" are also connecting online in the age of Web 2.0 to view, share, and comment upon both amateur and professional pornography. Grossman imagines that You are using the global reach of the Internet to access to information that will facilitate greater understanding of others, but You are also utilizing the web to as a gateway to a spectrum of pornography so broad that, as one commentator states, "there's something for everyone" (Hoffman).

Drawing on the veritable overload of pornographic content available on the Internet, Porn 2.0 sites bring together "tagged content, discussion groups and user comments and ratings to form a community where users can easily explore and share different fetishes and fantasies" (Freeman). As with other SNSs, many of the Porn 2.0 websites have applications to enable a user to access the site via a smartphone or a tablet computer. The websites also feature homepages where, like YouTube, there is a "Videos Being Watched Now" section and some version of the links offered on the popular YouPorn.com: "New Videos"; "Categories" (where a user can search by different sex acts and/or the physical appearance of those featured in the video); "Live Cams" (including "Bondage Cams," "College Cams," and "Curvy Cams"); "Recommended to You" (a personalized list of videos compiled through algorithms); "Top Rated"; and the omnipresent "Most Viewed." Like the options available to a YouTube user, a Porn 2.0 user can login to comment upon other videos, upload content, or to search the site. Porn 2.0 sites have many different designs-for example, the homepage of PornHub.com provides both a sexual orientation and language option, while shooshtime.com's homepage features links to nonsexually explicit videos-but the basic function remains the same. Essentially, the sites function as aggregators of Internet pornography, collecting and posting videos from users who source material from across the web. Still, in the vein of YouTube and Facebook, these aggregators say a number of things about the audience: what they are watching, when they are watching, and how often they are watching. (How we collect these particular findings is another project altogether, and it will no doubt .) Moreover, the identity of a Porn 2.0 user begins to be crafted with a range of "definitive" firsts that have been associated with YouTube: "the first clip, the first view, the first thumbs-up and down, the first viral video, the first copyright-infringement claim, the first lost afternoon" (Jones 28). And while YouTube is the frame of reference for both the Porn 2.0 website designer and user in regards to usability, Porn 2.0 is packed with all that YouTube forbids. 
Moreover, this platform enables freer circulation of the kinds of professional pornography that have been available on the Internet since the inception of any kind of moving images online, but one of Porn 2.0's more intriguing aspects is the prevalence of videos tagged as "amateur" or "homemade" on many of the sites. On xvideos.com, there are nearly 44,000 amateur videos; on Pornhub.com, the amateur category is second only to the "Pornstar" category in total amount of videos; on MadThumbs.com, numerous amateur videos shot on webcams have been viewed over 100,000 times. Despite claims of authenticity and being uploaded by users, it is apparent that many of the so-called amateur videos are in fact staged to look that way. Russell Goldman points out that when the "first true amateurs began posting images of themselves online in the early days of the Internet, porn companies found they could create similarly stripped down (sic) Web sites that looked like they had been created by the girl next door but that were really produced by the companies." Therefore although it can be at times difficult to distinguish between homemade pornography and those videos with participants who are being paid to engage in sexual acts (and/or are making a video for the primary purpose of generating a profit), the ease of cybercirculation for the former is one of the major markers of the Porn $2.0 \mathrm{era}^{2}$

This part of Porn 2.0 has irrevocably changed the pornography industry as a whole. While Porn 2.0 continues to grow, profits and sales from professionally produced DVDs have dipped since the mid-2000s (Freeman). But regardless of whether a user is watching professional, amateur, or even "fake" amateur pornography, a compelling element of Porn 2.0 is how it allows for a microidentity where the primary binding element is the ability to view sexual behavior in its myriad of forms, and the user's identity can be both anonymous and ephemeral, or registered and logged in under a username. The digitalized friendship made possible on Facebook and Twitter, where one's social circle is a visible collection of online profiles and walls, finds its counterpoint in the Porn 2.0, where acts of sexual intimacy on video--both live and recorded--are the currency of users and create a shared, albeit fantasized community.

\section{"Our New Private Lives”}

The online self who frequents PornHub or RedTube is, in turn, just one of a plethora of potential online identities. In "Our Fractured Online Identities," Jeff Atwood refers to Laurel Krahn and Anil Dash, two bloggers who have been publishing writing online since the late 1990s and currently have a combined 60 online profiles spread across the same amount of websites. Amongst the established SNSs of Facebook, MySpace, YouTube, Twitter, and the workplacenetworking LinkedIn, these profiles include Flickr, the popular photo sharing website; Pandora, a personalized Internet radio station; and Skype, the free, live video chat service. Attwood argues that the number of websites where Krahn and Dash have accounts and user profiles demonstrates a quantifiable fracturing of identity, and then asks, "Which one of these websites represents the real Laurel Krahn, the real Anil Dash? Or do all of these tiny fragments of identity cumulatively sum to a whole?" Asserting that one can measure which of these receive the "lion's share of attention" (presumably by how regularly user-provided information is updated and shared), Attwood argues that still "it's unclear" if one or more of these online presences represents the socalled real subject.

Rather than attempting to quantify what might constitute the single most authentic online profile, one can argue - as Attwood does - that all these micro-identities together constitute who we are 
online, from the single Tumblr blog post to the final image in a Flickr photo album. Whether it is by starting a single Facebook account or by possessing online profiles across numerous websites, the creation of different, interconnected selves online is not merely an inherent part of Web 2.0 but can be traced to the origins of cyberspace. In a 2002 article in the Journal of Applied Psychoanalytic Studies, John Suler addresses identity management in the early era of cyberspace, arguing that the fracturing of one's identity online-a phenomenon that goes back to the creation of a persona or avatar in the World Wide Web's original chat rooms and discussion boards- is a practice that relates to human psychology beyond online spaces. Suler states that the compartmentalization "or dissociating one's various online identities like this can be an efficient, focused way to manage the multiplicities of selfhood." Citing William James's pioneering work in American psychology and the subsequent development of role theory, Suler further argues that "cyberspace living is yet another manifestation of [the] shifting, juggling" of roles and responsibilities that begins during childhood. In addition to managing one's divergent Facebook and Twitter identities, for many Internet users one's online selfhood includes time and effort spent cultivating a porn identity.

The reason why I have briefly deviated from directly attending to sexually explicit social networking sites-in favor of reflecting upon how one conceptualizes online identities-is because much of the research on SNSs has failed to consider the Porn 2.0 phenomenon. ${ }^{3}$ Although it (like YouTube) is a communal Internet space where the viewing, discussing, and sharing of videos is the primary focus, Porn 2.0 may have been omitted from discussion about social networking due to the negative feelings associated with online pornography. In an article that discussed the production and economic realities of producing pornography, Edward Cone states that in the course of his research and interviews with those associated with the industry that shame remains "a surprisingly strong downer in [online] porn." But it is perhaps less important to consider the lack of academic discussion of Porn 2.0 as an act of direct sexual repression. In reference to Foucault's theorization of the discourse of sexuality - where it is "not to determine whether one says yes or no to sex ... [but rather] who does the speaking [and] the positions and viewpoints from which they speak" (11) - those who have done "the speaking" about online identities and social networking have omitted the porn identity. If various online identities express tastes and details from our personal lives, thus revealing our predilections on forums like Facebook wall posts and Twitter updates, should we not also consider the places where Internet users leave record of their sexual predilections? Trending topics on Twitter and reposted links on Facebook impart the concerns and interests of individual users and online social networks as a whole; the reposting and rating of material on Porn 2.0 websites do the same: We are what we post.

While Suler does not directly discuss the managing of online identities in the pornographic realm of cyberspace, parts of his theorizing do provide a constructive lever into considering online identities for Porn 2.0: particularly those subjects who, in Suler's words, "desire to lurk" and want "to look, but not be seen." In the world of SNSs, the lurker is faced with obstructions that impede his or her voyeuristic impulses. For example, even though an Internet user can gain varying degrees of access to Twitter and Facebook without owning an account and being logged in, the ability to freely search the sites ranges in levels of difficulty. The privacy settings employed by the websites and other users create blockades to the surfing of even fully registered users; between possessing an active account and not is a cyberspace of difference. Even in the 
world of Porn 2.0, where lurkers can access countless videos without logging in, certain realms are blocked (for example, live cam usage and sharing videos across websites). But what Shuler calls the lurker's desire "to hide completely ... [ [showing a] need to split off his entire personal identity from his observing of those around him" is useful to note in an increasingly personalized World Wide Web.

First, is it possible to "hide completely" online when one's tastes and preferences are measured and recorded even if a user is not logged in as a registered? Porn 2.0 websites contain heuristic algorithms designed to suggest other analogous pornographic videos and sites, a function that keeps with Google CEO Eric Schmidt's belief that it will become progressively more "hard for people to watch or consume something [online] that has not in some sense been tailored for them" (qtd. in Jenkins). As is the case with Amazon, Yahoo, Google, and countless other locations in Web 2.0, the algorithmic tailoring occurs the moment a user clicks on content that has been tagged and classified. Therefore our viewing (or repeated viewing) of particular videos starts to sketch not only what we like but also a measurement of who we are online, and the initial lines of that sketch-from what "category" of sexual behavior we select on a specific Porn 2.0 website-serves as leaving a first impression that will show the range and specificity of our desires. Porn 2.0 websites enable and record sexual tastes that we may not otherwise share with our partners, friends, and family, and the spectrum of possibilities for the online identity embodied when engaging in Porn 2.0- playful, serious, fleeting, addicted — can be expressed and experienced while connecting with a seemingly endless assortment of content. According to research related to the Porn 2.0 phenomenon and conducted in 2007, "every day there are 266 new porn sites on the Net. Every second, 28, 258 users are viewing porn" (Freeman).

Second, the heuristic relationship between these sites and those who use them-evident through the recommended videos and suggestions/advertising for other websites with similar contentcauses an uncanny sense of micro-identity, despite the user's relative anonymity. Everywhere in Porn 2.0 we are met with pornographic material that not only shows us what we have fantasized about, but also anticipates where else our fantasies might go. This uncanny sense of identity extends from the lurker who receives a list of recommended videos and chat partners based on the videos she has watched, to the user who has uploaded a video of her own sexual activity with partner (or partners); the latter, of course, experiences the uncanny sensation of viewing the rating and comments on her sexual activities from other members of the Porn 2.0 community. Writing about online communities and those who populate them, Danah Boyd argues that, "in order to exist online, we must write ourselves into being" (15). Of course, the information that a user readily provides is a conscious writing of our online existence: name, age, relationship status, photos, likes and dislikes, threads of communication with others in an online community.

Yet the ways that we write our way into being online is not just through the accoutrements of a Facebook profile or by making multiple comments about a video, but also through more subtle actions - the "liking" or rating of a particular still or moving image-that contribute to the wider online community. In "Being Online: Group Identities and social network identities," Andy Oram tells us to remember that even online "identity is a group construct, not an individual one. If we never took part in groups, our personal identities would scarcely matter." This sense of community is an admittedly subdued but nonetheless crucial element to Porn 2.0: with the click of the mouse a user can move between watching a video of group sex to a live video chat to 
facilitate mutual masturbation, before visiting the comments section to rate both experiences. Without drawing on elements of other SNSs, in particular how the websites "allow you to both chat with other posters online and read their profiles" and how they interconnect "social networking with completely free-of-charge pornography" (Freeman), Porn 2.0 would merely replicate previous popular forms of online porn. Here, both the lurker and the uploading/commenting user are essential to the formation of the online porn community.

\section{"The Ethics of Porn 2.0"}

Thus far, I have yet to speak to some of the ethical and legal issues facing those who participate in Porn 2.0, especially in the context of the homemade videos that can be found on most Porn 2.0 sites. ${ }^{4}$ One pertinent question relates to consent for the submission and subsequent circulation of amateur pornography via these sites. In early 2009, The New York Times' resident ethicist approached this question in a case study that epitomizes one of the major concerns for online pornography and social networking. A Times reader claimed to have come across a "short video clip on an amateur pornography site" of a friend who is "now a medical professional, wife, and mother" (qtd. in Cohen). Suspecting that the friend was not the Porn 2.0 user who uploaded the video, the reader sought advice about whether or not to inform her. The ethicist directed the reader to tell the friend that the video was available on a Porn 2.0 site, and further suggested that there is "the off chance that she already knows about this video because she posted it (and no reason she should not). The intimate lives of even our closest friends can be a mystery" (Cohen). This exchange broaches issues that are relevant to both users and facilitators of Porn 2.0 sites. First, it is possible that some of these homemade videos featured on the site were acquired through unethical and illegal means: material taken from stolen computers, accessed through hacked accounts, or uploaded by one of the participants in the sex video without the permission of the other(s). Notably, a number of the most popular Porn 2.0 websites feature advertising for and links to other sites that claim to have "hacked" and "leaked" amateur videos. 5

Second, those who post illegally obtained sexually explicit material-no matter whether it is an amateur or professionally produced video-are not the only potentially guilty subjects. As Edward Cone attests, the Porn 2.0 website operator could be liable: "post a picture of an underage model or an unsuspecting or of an unsuspecting subject caught using the toilet, and you could end up in court. Ditto if you're caught with copyrighted pics that aren't yours." Moreover, legislation relating to pornography is by no means static, adding further uncertainty to how Porn 2.0 might function in the future. Cone points out that there is "the prospect of obscenity prosecution, which some people fear could increase with a Republican administration" (Cone). As in the case of Web 2.0, Porn 2.0 is subject to not only advancements in technology, but also the context of changes in both the political climate and the accompanying regulatory decisions. Porn 2.0 websites' applications of T-Mobile's Android and Apple's iPad are not the only signposts of Porn 2.0's pervasive future(s); the legal ramifications that have effected the production and distribution of traditional pornography also apply to online porn's vanguard.

By referencing the potential invocation of obscenity laws, I return directly to the writing of one's online micro-identity in the Porn 2.0 era. When taking part in a social networking site where there is the possible availability of illegal content due to the relative ease and freedom in which users can upload material—videos that may breach privacy and/or copyright laws— the question 
of complicity applies to both the lurker and the registered, active user. In this way, one's behavior when inhabiting an online identity in the fantasy space of Porn 2.0 has real-world consequences: prosecution resulting from the downloading or uploading of sexual explicit material. Although this essay was borne out of attention given to the increasing amount of homemade pornography available in the territory of Porn 2.0, the extensive array of the most popular, available on the Internet sex videos-including professionally produced videos that feature consensual homosexual and heterosexual "intercourse, bondage and discipline, interracial anal intercourse, urination, and cumshots" (Fisher and Barak 318)-elicits thought about not only the transmission but also the reception of such material. Applying social psychology theory to the viewing of pornography, William A. Fisher and Azy Barak inquire about the reception of sexually explicit material online:

Is it the case that what the researcher designates as violent pornography is spontaneously perceived and interpreted by the average male as an endorsement of the utility and normativeness of violence against women? Is it the case that what the researcher designates as erotica is spontaneously perceived and interpreted by the average female as a nondegrading sexual portrayal? (313)

The authors proceed to demonstrate that an Internet user's distinctive perception and interpretation is a central consideration to understanding the phenomenon of Internet pornography; additionally, Barak and Fisher's study further confirms that the ethical issues about sexually explicit material does not apply merely to usage and permission, but to the sex acts depicted on the videos. ${ }^{6}$ For example, one of the popular categories and tagged description on a number of Porn 2.0 sites is for "Teens" or "Teenagers." Numerous sites ask for a confirmation of age for users (an admittedly token attempt to ensure that users are at least 18 years old) but there is no way to ensure that those engaging in sex acts on the videos meet the age of sexual consent. Moreover, the videos circulating in Porn 2.0's corner of cyberspace come from many different countries, where both age of consent and laws related to the production of pornography can vary. If a Porn 2.0 user were to download a video where the participants are minors, he or she could be charged with the possession of pornography; if the user, in keeping with the spirit of Porn 2.0's social networking element, then shared the video with others, he or she could conceivably charged with the even more serious crime of the distribution of child pornography. Fisher and Barak's important research into the psychological effect of online pornography on individual users, which was conducted before the boom of Porn 2.0 sites, would be helpful in considering online pornography today. Both these strands-the wider debates about pornography and the specific work done about audience reception-need to be extended as a way of further investigating the effects and implications of Porn 2.0's growth.

Additionally, the array of research on non-pornographic SNSs can provide useful theoretical levers for the study of Porn 2.0. Laura E. Buffardi and W. Keith Campbell's "Narcissism and Social Networking Sites," for example, picks up on the research focused on self-perception and presentation of the self to others in SNSs, arguing first that narcissism is "linked positively with relationship formation" (2008: 1304). Citing numerous studies, Buffardi and Campbell then state that SNSs are

built on the base of superficial "friendships" with many individuals and "sound-byte" 
driven communication between friends (i.e., wallposts)...(And) past research shows that narcissists, for example, are boastful and eager to talk about themselves, gain esteem from public glory, are prevalent on reality television, and enjoy looking at themselves on videotape and in the mirror (1304).

While Porn 2.0 websites not have individual walls for users-a key feature of the most popular SNSs today-the soundbite-style communication that marks the relationships between users on other social networking sites is present in their pornographic counterparts. The forums and video comments section on shoostime.com, one of the first major Porn 2.0 websites, regularly contain brief remarks about the quality of the video, both in regards to the content and the clarity and definition of the live stream. Even with the live cams that facilitate interaction between users and featured "Porn Stars"- a feature that, on many Porn 2.0 sites, often requires payment for access - the exchanges are primarily made up of epigrammatic questions and greetings ("HI SEXXXY!" and "hey beautiful") and answers ("I live in Michigan" and "I can do that for you, baby"). The video comments sections are similarly pithy; the following is the first three comments from a video of a heterosexual couple engaging in intercourse: "Stop lying about the video quality of the download"; "We can all tell the original source links point to crap-quality iPhone video"; and "nowadays you need 4 comments to get your point across." These kinds of comments could conceivably be found on any number of YouTube videos; the difference, in this case, being not of the form or the message but the content of the video to which it refers.

\section{Conclusion}

Where to from here? SNSs create group data, so we'll see what comes from this most recent, measurable groupo. But this doesn't mean that conclusions have been made: Social psychologists have defined narcissism in online social networking-those subjects who "gain esteem from public glory" and "enjoy looking at themselves on videotape and in the mirror"-is clearly evident in Porn 2.0. In this way, a segment of cyberspace where a user can not only upload a video of herself engaged in sex acts, but can also gauge its popularity through the comments, rating, and number of hits given to a video. While this online "public glory" mays be draped in anonymity, on visiting the amateur video section of any number of Porn 2.0 websites, the narcissism of Web 2.0 appears to extend to our online sex lives, too. But more than just an opportunity for the Internet user to create another online identity, or to satisfy narcissist tendencies that can be indulged across any number of SNSs, Porn 2.0, like YouTube, allows us to gauge a great deal about the Internet's wider "userdom." Marking the sixth anniversary of YouTube, Chris Jones maintains that the site "represents the triumph of mathematical fact. It provides a perfectly calibrated list, hundreds and thousands of entries long, of the things we like and the things we don't like quite as much and the things we like least of all" (28). Porn 2.0 websites make available a similar set of data but within the much more narrow scope of visual media: online pornography. Reminiscent of YouTube, Porn 2.0 can measure an aspect of the intimate lives-sexual tastes and predilections that might not be shared with others or recorded anywhere else-of the online-networking, Time-celebrated You. Furthermore, if, as recent research has shown, Internet users consider their "online personae . . . [and] identity as an extension of their real-life self" (Hart, Johnson, and Stent), then Porn 2.0 is a particularly fertile ground for getting to know the real You. 


\footnotetext{
${ }^{1}$ Tim O'Reilly “Design Patterns and Business Models for the Next Generation of Software” (available at http://oreilly.com/web2/archive/what-is-web-20.html) is a comprehensive assessment of Web 2.0, authored in 2005 by one of the foremost theorists dealing with emerging technologies. In the article, O'Reilly lists a number of transition points in the movement from Web 1.0 to Web 2.0. A more recent piece, "Web Squared-Web 2.0 Five Years On" (written with John Battelle and available at http://www.web2summit.com/web2009/public/schedule/detail/10194), conveys the changes that O'Reilly has witnessed since anticipating the advent of Web 2.0.

${ }^{2}$ Yet the majority of sexually explicit videos available at the websites that I am referencing still conform to wellestablished porn conventions: there is often one or more camera operators; those engaging in sex are talent under the guidance of a director and the direction of some form of script; and, most importantly, the videos are a commercial enterprise.

${ }^{3}$ See Harsha Gangadharbatla's recent article "Facebook Me: Collective Self-Esteem, Need to Belong, and Internet Self-Efficacy as Predictors of the iGeneration's Attitudes toward Social Networking Sites" (available at http://jiad.org/article100)

${ }^{4}$ I have not referenced ongoing academic discussions about pornography, particularly as it relates to gender and critiques of the pornography industry as a whole. My reticence to address these important debates about pornography has been due in part to the length of this essay, where I have only begun to argue the ways that the Porn 2.0 user is an online micro-identity worthy of critical attention.

${ }^{5}$ As mentioned earlier in this piece, it can be difficult to ascertain the veracity of a Porn 2.0 video's classification. ${ }^{6}$ Barak and Fisher's article is an extremely detailed and demonstrates how pertinent research into audience reception of Porn 2.0.
}

\section{References}

Ahn, Y Et al. (2007) 'Analysis of topological characteristics of huge online social networking services', Proceedings of the 16th international conference on World Wide Web, May. Available from: http://www2007.org/papers/paper676.pdf

Arthur, C. (2011) 'Just how much pornography is there online?', The Guardian, November. Available from: http://www.guardian.co.uk/technology/2006/nov/23/guardianweeklytechnologysection2

Attwood, J. (2007) ‘Our Fractured Online Identities', codinghorror.com, December. Available from: http://www.codinghorror.com/blog/2007/12/our-fractured-online-identities.html

Boyd, D. (2006) 'Friends, friendsters, and top 8: Writing Community Into Being on Social Network Sites', First Monday, 11.12, March. Available from: http://firstmonday.org/htbin/cgiwrap/bin/ojs/index.php/fm/article/view/1418/1336

Buffardi, L. and W. Campbell. (2008) 'Narcissism and Social Networking Sites', Personality and Social Psychology Bulletin, 34.10: 1303-1314.

Cohen, R. (2009) 'The Porn Identity', The New York Times, February. Available from: http://www.nytimes.com/2009/02/22/magazine/22wwln-ethicist-t.html

Cone, E. (2002) 'The Naked Truth', Wired, February. Available from: http://www.wired.com/wired/archive/10.02/sex.html 
Fisher, W. and A. Barak (2001) 'Internet Pornography: A Social Psychology Perspective', The Journal of Sex Research, 38.4: 312-323.

Foucault, M. (1988) The History of Sexuality. New York: Vintage Books.

Freeman, S. (2007) 'Porn 2.0: What Happens When Free Porn Meets Social Networking', Alternet.org, July. Available from: http://www.alternet.org/sex/56414/?page=entire

Goldman, R (2008) 'Do It Yourself! Amateur Porn Stars Make Bank', abc NEWS, January. Available from: http://abcnews.go.com/Business/SmallBiz/story?id=4151592\&page=1

Grossman, L. (2006) 'Time's Person of the Year: You', TIME, December. Available from: http://www.time.com/time/magazine/article/0,9171,1569514,00.html

Hart, M. Et al. (2007) 'More Content-Less Control: Access Control in the Web 2.0', June. Available from: http://www.cs.stonybrook.edu/ rob/papers/cbac-w2sp07.pdf

Helmore, E. (2007) 'Home porn gives industry the blues', The Observer, December. Available from: http://www.guardian.co.uk/world/2007/dec/16/film.usa

Hoffman, C. (2007) 'Obscene Losses', Portfolio, October. Available from: http://www.portfolio.com/culture-lifestyle/culture-inc/arts/2007/10/15/YouPorn-VividEntertainment-Profile/index $3 . h t m l$

Jenkins, H. (2010) 'Google and the Search for the Future', The Wall Street Journal, August. Available from: http://online.wsj.com/article/SB10001424052748704901104575423294099527212.html

Jones, C. (2011) 'The Anniversary: YouTube, 6', Esquire, February: 28.

Lange, P. (2007) 'Publicly private and privately public: Social networking on YouTube', Journal of Computer-Mediated Communication, 13.1. Available from: http://jcmc.indiana.edu/vol13/issue1/lange.html

Oram, A. (2009) 'Being Online: Group Identities and social network identities', Radaroreilly.com, December. Available from: http://radar.oreilly.com/2009/12/onlineidentity7.html

Suler, J. (2002) 'Identity Management in Cyberspace', Journal of Applied Psychoanalytic Studies, 4. Available from: http://users.rider.edu/ suler/psycyber/identitymanage.html 